\title{
Obstacles, Networking Approaches and Entrepreneurial Network Changes
}

While recent work has considered network change, little is known about how certain factors determine such changes. This study focuses on two factors - the type of obstacles entrepreneurs face and their networking approach - and employs a two-stage research design and network visualisation approach to capture entrepreneurs' experiences in managing networks during their entrepreneurial journey. Using an inductive approach, the first stage of the study identifies the obstacles and networking approaches that influence different types of network changes. The second stage employs a deductive approach to test the hypotheses developed from the first stage using a larger sample. We find that in experiencing obstacles from internal sources, entrepreneurs are more likely to find support from weak ties while strong ties are beneficial for overcoming obstacles from external sources. In having difficulties in acquiring entrepreneurial knowledge and skills, entrepreneurs are more likely to develop a low-density network consisting of many structural holes. Conversely, dealing with difficulties in accessing market and resources imposes over-reliance on high-density network. Furthermore, the entrepreneurs' networking approaches also influence network changes and partially mediate the relationship between the networks and the obstacles they face.

Keywords: entrepreneurs; obstacles; networking approach; network change 


\section{Introduction}

Social networks are especially important for entrepreneurs, helping to mitigate the liability of newness and smallness (Aldrich and Reese, 1993). When entrepreneurs face uncertainty about their future and/or experience challenging tasks, such as exploiting opportunities, exploring markets, and engaging with customers (Dyer et al., 2008), they resort to their network for help and resources (Elfring and Hulsink, 2007). How entrepreneurs engage their networks for resource acquisition has long been studied (e.g., O'Donnell et al., 2001; Hoang and Antoncic, 2003; Jack, 2010; Street and Cameron, 2007; Sullivan and Ford, 2014; Perry-Smith and Mannucci, 2017). These studies have tended to focus on the characteristics of networks, such as typology, structure, and the quality of relationships (Nahapiet and Ghoshal, 1998; Anderson and Jack, 2002; Reagans and McEvily, 2003; Semrau and Werner, 2014). What studies have also shown is that networks are not static, but evolve in response to changing resource needs, which in turn compel changes in the entrepreneurs' networks (Johannisson, 1986; Hite, 2005; Koka et al., 2006; Hallen, 2008; Slotte-Kock and Coviello, 2010). By changing their networks, entrepreneurs are more likely to survive environmental jolts (Venkataraman and Van de Ven, 1998) and experience superior performance (Baum et al., 2000). However, this dynamic nature of networks and the factors that might influence change have not been addressed to any real extent. Therefore, we fail to fully recognize that the problems entrepreneurs' face may actually constitute a key reason to strategically choosing to build and maintain different network relationships (Porter and Woo, 2015). Therefore, the network antecedents and what contributes to the network dynamics and configurations require further study (Brass et al., 2004).

Addressing research questions on how entrepreneurs' networks change as a result of new emerging needs, is decidedly challenging due to ambiguities relating to the individual's situation and context. The difficulty of investigating network changes is compounded by the fact that this is difficult to observe. Following Vissa's (2012) suggestion, the present study uses a two-stage research design to overcome this difficulty. In the first stage, an inductive approach using visualisation techniques in the form of network mapping is used to identify the factors that force a network change and the network characteristics entrepreneurs develop as a response to these factors. In the second stage, a survey is used to test the model developed in stage 1 . As we will show, the research focuses on obstacles entrepreneurs come across in their entrepreneurial process that may force a network change. Furthermore, such obstacles may trigger different networking actions aimed at adding new contacts versus managing existing contacts (Perry-Smith and Mannucci, 2017; Vissa, 2012), which in turn may induce a network change. As networks can change through coincidental events or can be strategically developed as a sense making process (Simsek et al., 2003), this study attempts to capture network change as a result of adaptively responding to the entrepreneurial challenge of overcoming obstacles or acquiring resources (Birley, 1985; O’Donnell, 2014).

The study makes three key contributions to the literature. First, it enhances understanding of how networks change during the venture development process. In this respect, we offer a response to calls 
to focus on factors explaining the evolution of entrepreneurial networks (e.g., Hoang and Antoncic, 2003; Jack, 2010; Slotte-Kock and Covielo, 2010; Gedajlovic et al., 2013; Porter and Woo, 2015). Second, our research sheds light on how obstacles can influence social network changes by revealing the direct and indirect mechanisms, with the latter mediated by the entrepreneur's networking approach. Third, visualisation techniques, such as the network mapping used in this study, provide a new nuance to traditional data collection methods to study networks. While there have been some recent development among network scholars in using visualisation as a tool, the use of this method to understand entrepreneurial networks is still limited. This study shows that by asking respondents to visualise their network in the form of a map, the study was able to collect rich quantitative and qualitative data of how network develops overtime. Taken together, the study highlights important considerations to understanding network changes in the context of entrepreneurship and offers new research avenues on how networks evolve to meet entrepreneurial requirements.

\section{The need to understand network changes}

There is extensive discussion in the entrepreneurship literature about the key benefit of networks in providing information, advice, and access to valuable resources. Early studies on entrepreneurial networks (e.g., Van de Ven, 1964; Aldrich and Reese, 1993) find successful entrepreneurs tend to be more network oriented and that their networks can involve a variety of individuals who are drawn on in the entrepreneurial process. Relationships with venture capitalists, professional, and business service organisations are a means of tapping into resources, talent, and market information (Sapienza, 1992; Sorenson and Stuart, 2001). Networks with distributors, suppliers, customers, and competitors can be an important conduit of information and knowledge (Jarillo, 1988; Brown and Butler, 1995; Street and Cameron, 2007). A number of studies (e.g., Birley, 1985; Jack, 2005) also find that entrepreneurs consistently use networks to obtain and refine ideas, gather information, and recognise entrepreneurial opportunities. As entrepreneurs experience constant change in their business needs and context, we may assume that entrepreneurial networks, as a means for survival, are dynamic and change overtime.

Research has further examined how networks change to support entrepreneurial activities. For example, Birley (1985) explored the transition of informal to formal relationships and how these relationships change when assembling key elements for the development of new firms. Larson and Starr's (1993) conceptual work on the role of networks in the venture creation process provides a model illustrating the change of network activities used to secure critical economic and non-economic resources for entrepreneurship. Jack (2005) finds that entrepreneurs' networks have a dynamic nature where dormant ties can be reactivated again as strong ties to support business activities. Hite (2005) argues that at the early stage, entrepreneurs rely on identity networks characterised by strong and close ties, but later expand their networks with more structural holes, known as calculative networks. More recent research examines how the evolution of entrepreneurial networks can influence venture 
growth and development (Davidsson and Honig, 2003; Hite, 2008; Hite and Hesterly, 2001; Jack, 2005; Elfring and Hulsink, 2007; Schutjens and Stam, 2003). Overall, these studies show that networks are not static but change as they evolve, so that the content and structure of the network can vary in response to entrepreneurial requirements at a specific point in time (Johannisson, 1986; Hite, 2005).

While the changing nature of networks has attracted much interest from scholars, the understanding on the nature of change and the factors that influence the change is relatively limited. Entrepreneurs may intentionally change networks for exploring opportunities and overcoming obstacles (Vissa, 2011) and therefore research must address two questions. The first question relates to the nature of the networks that are created by entrepreneurs in response to their entrepreneurial needs. In network studies, the literature is still debating what type of network, i.e., structural or relational (Adler and Kwon, 2002), can benefit entrepreneurship. Some scholars, for example, Burt (2000) and Baum et al. (2000), propose that benefits derive from the structural characteristics of networks, such as structural holes. Other scholars, for example, Podolny and Baron (1997) and Granovetter (1982), argue that the relational characteristics of networks, such as strong or weak ties, can also provide benefits. However, as the network changes over time, different network formation and characteristics should be developed in order to receive benefits from both structural and relational characteristics of networks. In other words, in studying entrepreneurial networks both network characteristics should not be treated independently. Jack (2010) and Slotte-Kock and Coviello (2010), in their reviews of research on network and entrepreneurship, specifically suggest new research directions to address key questions such as when and through what process ties are selected for entrepreneurship.

A second question relates to which antecedents influence an entrepreneurs' network choices (Brass et al., 2004). Although networking is one of the most common practices in business settings, research lags behind in providing a compelling theoretical rationale for how and why individuals develop networks (Hoang and Antoncic, 2003; Porter and Woo, 2015). It is also unclear how personality and individual approaches influence the characteristics of networks. As the literature argues that entrepreneurs' goals can influence their instrumental mind-sets and social network activation (Shea and Fitzsimons, 2016), these factors arguably influence the decision to expand, reduce, or replace contacts in their network.

Since we know little about the networks that entrepreneurs form and which factors influence change, we carried out a two-stage research study that views the issues under investigation from both a positivist and interpretive perspective (Uzzi and Gillespie, 2002; Vissa, 2012). The first stage is thus an inductive examination of network change and the factors that influence change while the second stage uses a deductive approach to investigate the relationship among these factors and network changes in a larger sample. 


\section{First-stage study}

\section{Research design}

Sample: The inductive part of this research is based on a multiple case study, which provides the background to defining the context and theoretical understanding (Yin, 2002). This also allows respondents to associate with their own context. In this study, six entrepreneurs from the Northwest region of the United Kingdom involved in a university-SME engagement programme were selected. The data collection was conducted over a 3-month period, with some respondents interviewed twice or more. The length of interviews varied in duration from a couple of hours to over six hours, while the direction of interviews was determined by the need to follow up the emerging themes created during the network mapping activity. As a result, we gathered rich information on the respondents' entrepreneurial journey, including factors that had hindered the development of their business. Table 1 shows the background details of respondents.

Table 1 here

Approach: As indicated earlier, the inductive approach best suits our aim of identifying network changes. Networks are a complex and hard to grasp subject, consisting of many different elements that can create data collection bias. To reduce bias and increase the validity of data collection, our approach allowed respondents to describe their network, but also to focus on revealing their past networking experiences. Rather than using traditional qualitative techniques, we chose to combine these with network visualization techniques and build a drawing model in the form of network mapping. Respondents were invited to imagine and then describe their network using drawing as a tool. We designed the network mapping activity as a means of data collection and at the same time provided respondents with a way to articulate the role of their network. As a result of our network mapping activity, the visual data produced from this activity can be regarded as a refined reflection of the respondents' networking strategy. The use of physical models or activities in explaining strategy is not new. Scholars such as Mintzberg (1987) and Piaget (1971) used a similar approach when discussing the task and process of strategy making.

We started the data collection process by inviting respondents to draw their current network. We then asked them to draw their initial network before starting the company. This was followed by semistructured interviews (Fontana and Frey, 1994) that were recorded and transcribed. The questions concerned the themes that emerged from the network, such as reason for contacting network partners. 
We posed questions such as 'why did you meet her/him?', 'why did you bring him into the network?' Moreover, we also asked several questions about the networking process, such as 'how did you get in touch with this person', 'how did you meet him/her', 'could you please explain the process of having him/her as your contact', 'did you known him or her previously?' These questions were not asked in any specific order, but were governed instead by the visual representation of their networks (Gummesson, 2000). We repeated this process again several time during 3-month. As a result, we collected several network maps, stories and detail information on network contacts as well as the content and quality of the relationships. The overall data collection process enabled a richer and deeper understanding of how entrepreneurs developed networks.

Figure 1 here

Analysis method: In analysing the data, we explored the themes using the constant comparative method (Silverman, 2006) and analytic induction (Glaser and Strauss, 1967). We independently read the interview transcripts and employed open coding using the qualitative data analysis program NVIVO. We also iteratively analysed all types of data by moving back and forth between the interview data, network maps, and the emerging structure of theoretical arguments that responded to the research questions (Locke, 2001). In the analysis, we created provisional category and first-order themes by identifying statements, drawing on common statements, expressions, and opinions to form provisional categories and the first-order themes. We also employed a contact summary form (Miles and Hubernman, 1994) to record the categories that emerged from the data. We then created the second-order themes. The themes were consolidated for each respondent. This stage enabled a comparison across data leading to a more theoretical and abstract understanding. As we consolidated the categories, we moved from open to axial coding (Locke, 2001). In the last step, we started to restrict the concept by aggregating the theoretical dimension into third-order themes. We began building several alternative models describing how these themes relate to each other.

Moreover, network maps produced by the study provide rich data on the characteristics of network and their change. We followed the current study on network by focusing on structural and relational dimension. Structural dimension focuses on the connection among network contacts where the network can be divided into low and high in terms of density. A long debate has occurred in the literature especially arguing the benefits of low-density networks compared to high density networks. In a low-density network, members of the network are loosely connected. According to the literature, this type of network enhances exposure to a diversity of information (Burt, 1992, 2000, 2004) and generates fewer constraints (Burt, 2000). As a result, the entrepreneurs benefited from exposure to a 
new way of thinking and solutions to problems (Hite and Hesterly, 2001; Koka et al., 2006; McEvily and Zaheer, 1999). A high-density network is when members are closely connected. In this type of network, the entrepreneurs' contacts are known and familiar to each other. Since connected contacts are likely to interact frequently, much of the information that circulates in the social system is redundant. As a result, a high-density network tend to impose strong norms on their members, but facilitate coordination, and are beneficial for information sharing (e.g., Uzzi, 1997). In our study, we asked the respondent to draw a line connection among their network contacts. This approach has been widely used in studying network density (Borgatti et al., 1998; Jensen and Greve, 2002).

The relational dimension refers to strong and weak ties. Strong ties provide trust, strong support and access to strategic information (Ruef, 2002; Chauvet et al., 2011). In our study, we found that strong ties help entrepreneurs overcome obstacles, bringing legitimacy, and access to resources and information (Cattani and Ferriani, 2008), as well as providing long-term support. In contrast, weak ties are beneficial as they are conduits to new and unique information (Granovetter, 1974). Thus, entrepreneurs are likely to seek out such ties when experiencing obstacles as this resource may be useful in addressing issues that they were unable to effectively address with their existing resources (Jack, 2005). In the study, we asked the respondent to measure the strength of ties based on the amount of time, emotional intensity and the frequency of interaction with each contact. Strong ties were measured as a long-term relationship, frequent interaction and a high degree of closeness while weak ties were characterised as a short-term relationship, infrequent interaction and a low degree of closeness. To visualise the relationship, thick line was used to illustrate strong ties and thin line for weak ties.

Overall, the methodological techniques provided sufficient depth of data to allow a meaningful analysis of network changes and the factors that determine these, as well as an in-depth understanding of the role of each contact in the network. This also established the common direction of network changes and allowed us to compare this with existing theories.

\section{Findings from the first study}

Based on the analysis of the data collected during the network mapping activity, the findings shows that entrepreneurs use their network contacts to deal with obstacles. Table 2 shows the transformation of the raw interview data to the obstacle categories.

Table 2 here

From the table above, it is clear that obstacles that influence network change can be categorised in two formative constructs (1) the source of obstacles and (2) the type of obstacles. Those constructs 
were developed from second order categories as explained below. With regards to the source of obstacles, the obstacles can be divided into internal and external obstacles. Internal obstacles relate to problems caused by the firms' or entrepreneurs' internal conditions that are unique and specific. An example of these obstacles is the entrepreneurs' technical or managerial capability as stated by Tom: 'the quickest way to solve my lack of skills in accounting and finance is to hire someone. However, at that time, we didn't have resources. We were lucky as my uncle knew someone who need an internship for a year. So we had him for a year and now he is working with us.' Moreover, difficulties related to financial control and accounting systems also constitute an internal obstacle. The entrepreneurs may also experience obstacles due to their business strategy and their capability to attract investments. The second type of obstacle experienced is external and rooted in the market and industry structure. Markets cannot be controlled, are independent of what occurs at the firm level, and have varying levels of uncertainty and unpredictability. Another source of external obstacles relates to the development of technology and government regulations. These obstacles have forced the entrepreneurs to develop new networks as expressed by Pete, 'when I started the business, I didn't aware about the complexity in meeting the European standards. None of us or my mentor understood the application process. The only solution is to seek help for the external expert.'

The second dimension of obstacles concerns the the type of obstacles. Here they can be categorised into access to market and resources and acquiring knowledge and skills, such as investment and research facilities. Ian is one of the most experienced entrepreneurs in our study, however, he faced obstacles in getting new investment. He could not rely on his current networks which then forced him to expand their networks aiming to have more investors. In developing his business, Tom relied heavily on university support 'the support from university was instrumental in the early days, the head of department allowed me to use one of unoccupied office. It helped a lot as I got access to free internet connection and also to students to develop the software.' Moreover the knowledge and skills related obstacles refers to difficulty experienced by entrepreneurs in accessing information about market, developing managerial and operational skills. Due to their limited business experience, most of the entrepreneurs seek help from their contacts. To illustrate the findings on obstacles, figure 2 shows the $2 \times 2$ matrix of the constructs with some examples.

Figure 2 here

Despite the fact that most literature on networks suggests entrepreneurs use networks to deal with resource scarcity, the findings add more nuance by revealing that in addition to obstacles faced by entrepreneurs, networks change as a result of the entrepreneurs' networking approaches. 
As shown in Table 3, approaches can be categorised into two formative constructs: (1) network expansion, and (2) network strengthening. The data shows that four of the respondent employed networking approach while another two prefer network strengthening approach. Using a network expansion approach, entrepreneurs tend to develop networks and use every event as an opportunity to meet people and develop new connections. They are aware that even strangers may possess resources they need or offer market opportunities. They understand that the resources in hand are limited and therefore need to expand their network. At times, their approach is rather unplanned as they meet some of their contacts accidentally. More often, entrepreneurs purposefully dedicate time and resources to making connections and develop a systematic approach, for example, by understanding their contacts' capabilities and using them to acquire resources. In the network strengthening approach, entrepreneurs turn to their existing contacts or network partners. Entrepreneurs rely on family and friends as sources of resources and information. At times, they reconnect with their old friends or colleagues. Entrepreneurs using this approach always ensure that trust is a priority in developing the network and hence invite network contacts with whom they have a long-term relationship to join their network. Our analysis also found that strengthening strong ties is facilitated by proximity. Being located in close proximity enables developing friendships that can be useful for the business. Moreover, entrepreneurs may also develop relational embedding where entrepreneurs combine social and business content in the relationship. Overall, a network strengthening approach requires more resources committed to managing the relationships, as trust needs to be developed between entrepreneurs and their contacts. As explained above, obstacles can trigger different networking actions aimed at adding new contacts or managing existing contacts (Perry-Smith and Mannucci, 2017; Vissa, 2012), which in turn can lead to network changes.

Moreover, the study confirm that for each individual, one networking approach was more dominant than the other. In a very few cases, the study recognise that network expansion and network strengthening is not mutually exclusive behaviour. Entrepreneurs may develop both strategies simultaneously. This was expressed well by Fiona 'I feel more comfortable to discuss my problem with people that I already know, people that I can trust. However, in a rare occasion such as dealing with this problem, I have pushed myself to be more open .. more adventurous and take opportunity to talk with other business.'

Table 3 here

In the next finding, the change of network will be discussed. Based on the network maps produced by the respondents during the data collection activity. As shown in figure 3, four patterns of network can be developed as a result of combination between structural and relational dimensions. The first pattern 
is a low-density network and weak ties where entrepreneurs develop an open and unconnected network. We found three respondents have frequently develop this type of network during our 3month study. This type of network is associated with exploration where respondents were purposefully looking for options and opportunities. The evidence also shows that most contacts are relatively new to the entrepreneur. This took the form of the network providing the inspiration for the entrepreneur (Tom) to relocate his office and to pursue a new opportunity 'a lot of people were puzzled as to why we decided to relocated her .. it's calculated business decision, it has endorsed by our business friends. Our business aims to serve global customer and the best place to access the network is to be here.'

The next pattern of network is a high-density network and strong ties, this network resemble a close and tight network where all contacts are connected. Most of the respondents have developed this type of network during their entrepreneurial journey. We found many evidence of growing relationships where a low-density network and weak ties grow into a high-density network and strong ties. The relationship with venture capitalists, business advisors, manager of incubators and other start-up in business incubators are belong to this category. An example of this network was found in our discussion with George when he not only received new investment but also access to the European market. 'I was introduced by my mentors, at the beginning I felt that I was entering a closed man club. You can feel that trust is very important for them. I worked on it and tried for not disappoint them. The current state of my business is indebted on their support.'

In another situation, the respondents developed a close network consists of a low-density network and strong ties. We found this type of network appears in the early stage but has changed significantly into a high-density network and strong ties. As the elements of trust and knowledge transfer are present, We found evidences that the entrepreneurs develop networks only with selected partners. The relationship have been built for a long time and have provided support for the entrepreneurs. Therefore, network are not well connected but contain many strong ties. Another potential combination of structural and relational dimension is the creation of social network where the entrepreneurs use a social club or business incubators as a part of their business networking. The Chamber of Commerce and industrial associations are places for this type of network. Those relationships may beneficial for entrepreneurs but we found a very few evidences of the role of this type of network in supporting the entrepreneurs in growing the business.

Figure 3 here

While the combination of structural and relational dimension may produce four patterns of network change, the study found that the majority of networks developed by the entrepreneurs are the 
combination of a high-density network with strong ties and the combination of a low-density network with weak ties. Both type of networks are consistent with the argument in the literature where the benefits of low-density networks are often associated with weak ties whereas high-density networks offer similar benefits to strong ties. As both network characteristics seems to be developed in a similar direction as suggested by the literature, the hypotheses for this study will look the patterns into a consideration where a low density network will be associated with weak ties and a high-density network will be linked with strong ties.

\section{Hypotheses development}

Based on the inductive studies focusing on the identification of obstacles and networking approach, we constructed hypotheses that predict the role of these factors in determining network changes.

\section{Obstacles, networking approach and their influence on network changes}

The first hypothesis deals with the link between the type of obstacles and the characteristics of entrepreneurial networks. Following the discussion in the literature, we argue that structural characteristics in the form of high and low density networks provide a better explanation for an entrepreneur's strategy for accessing different types of obstacle. In starting a new venture, entrepreneurs need to access new knowledge and skills such as management, finance and deal with government regulations. In this case, entrepreneurs rely on a high-density network. Many scholars (e.g., Podolny, 1994; Sjöstrand, 1992) argue that in transferring knowledge, especially tacit knowledge, people tend to form an alliance with others who share similar values. In situations where entrepreneurs need to deal with tacit knowledge, relationships based on trust will nullify the threat during the exchange process. Besides support from friends and family, a high-density network sometimes in the form of an incubator community helps entrepreneurs to not only solve the obstacles together but also provide a motivation boost and peer-learning opportunity. Pete shared his view on the role of community spirit at the incubators in helping him to cope with the pressure. 'Starting $a$ business is a lonely process, you have to make decision every day and no-one helps you. Having located here, I can learn from other start-ups. It gives me moral support as I see them in similar situations. We also share our thoughts and even our problems without reservation. Usually it happens during coffee breaks or lunch time.'

On the other hand, the literature suggests that a low-density network with unconnected contacts are beneficial as they are conduits to new and unique information (Burt, 1992; Sullivan and Ford, 2014). Thus, entrepreneurs are likely to seek such networks when experiencing problems in growing the business, since the information offered by these contacts may be useful in addressing obstacles that the entrepreneurs have been unable to address previously (O’Donnell, 2014). Entrepreneurs may 
need to look for new investment or facilities or open new markets. Dan echoed this argument, 'when I entered new market, the whole business ecosystem is different. I need new contacts in order to become a part of their system and network. In my experience, I don't need to many contacts .. but they should be in the strategic place and important for my business.' Overall, a low-density network with structural holes offers diversification in market information and resources needed to grow the business. Thus, we propose the following hypothesis:

H1. Entrepreneurs develop (a) a high-density network to acquire entrepreneurial knowledge and skills and (b) a low-density network to access market and resources.

Internal obstacles are unique to entrepreneurs and arise from internal turbulences, such as entering a market or experiencing administrative, financial or accounting problems. In this situation, entrepreneurs tend to seek a solution and/or information in their attempt to reduce or manage these obstacles. Strong ties consisting existing and long-term contacts are less relevant in such situations and internal capabilities have no function (Beckman et al., 2004). In contrast, weak ties may offer important information and knowledge to overcome these obstacles as stated by Ian 'when I faced issues with my business .. let's says accounting and tax issues, problems with my employee, I usually asked for reference. Otherwise, I rely on internet to find service and solution. I have this guy on my contacts, he works for university. He gave me access to students and staffs and.' As a result, entrepreneurs develop a relationship with weak ties in order to deal with internal obstacles.

In contrast, external obstacles are uncontrollable and are independent of what occurs at the firm level. Fiona got herself into a difficult situation when her first project failed due to the changing situation of the contractors. The situation was out of her control but she persisted to finish the project. Finding solutions from new contractors would be very challenging for her. Instead, she persuaded her close friend to rearrange their existing work and work for her project. We argue that in responding to these threats and obstacles, entrepreneurs may reinforce their existing networks. Strong ties such as friends, family, existing partners or even dormant ties are useful in this situation as they offer stability, trust, and certainty of commitment and support. Galaskiewicz and Shatin (1981) find that in turbulent environments, individuals rely on their past or current partners, while Gulati (1995) finds that individuals select partners that they know well to reduce the turbulence and difficulties resulting from strong competition. Based on this argument, we propose the following hypothesis:

H2. Entrepreneurs develop (a) weak ties to deal with internal obstacles and (b) strong ties to deal with external obstacles.

The findings from the inductive study show that network changes can derive from the networking approach, namely, network expansion or network strengthening. In a network expansion approach, 
entrepreneurs actively use formal and informal events to develop new ties (Shipilov et al., 2007). This approach produces networks that are not well connected while the presence of new contacts increases the number of weak ties in an entrepreneurs' network. In contrast, entrepreneurs with a network strengthening approach develop relationships based on trust and other factors such as common background, affiliation, and friendship. Obstafeld (2005) argues that individuals tend to initiate relationships with their existing network contacts (tertius iungens orientation). As a result, the networks are characterised by high density and strong ties. As entrepreneurs adopt different network approaches related to network change (Nahapiet and Ghoshal, 1998; Inkpen and Tsang, 2005; Ahuja, 2000; Zaheer and Bell, 2005), we propose the following hypothesis:

H3a. Entrepreneurs with a network expansion approach tend to develop a low-density network and weak ties.

H3b. Entrepreneurs with a network strengthening approach tend to develop a high-density network and strong ties.

\section{Networking approach as a mediator of the relationship between obstacles and network changes}

The previous hypotheses argue that obstacles and networking approaches determine whether entrepreneurs construct their network. Nevertheless, entrepreneurs' networking approaches cannot be adopted independently of the obstacles they experience. As explained earlier, entrepreneurs tend to develop a low-density network to overcome obstacles in getting access to market and resources and a high-density network to acquire knowledge and skills. Strong ties are arguably important for acquiring external obstacles and weak ties are effective for finding solutions for internal obstacles. For specific types of obstacles, a certain approach is more relevant as this creates the type of network that fits with the entrepreneurs' need. Therefore the entrepreneurs' networking approach is aligned with their efforts to deal with the obstacles they face, which later influences entrepreneurial network characteristics and changes. Accordingly, the networking approach acts as a mediating variable. We thus construct further hypotheses:

H4a. A network expansion approach mediates the relationship between obstacles such as difficulties to acquire entrepreneurial knowledge and skills and the formation of a low-density network as well as the relationship between internal obstacles and the formation of weak ties.

H4b. A network strengthening approach mediates the relationship between obstacles such as difficulties to access market and resources and the formation of a high-density network as well as the relationship between external obstacles and the formation of strong ties.

\section{Second stage study}

\section{Research design}


Sample. The sample of the second study consists of 80 entrepreneurs located in the Northwest region of the United Kingdom who attended a series of half-day workshops. A maximum of 20 entrepreneurs participated in each workshop. The respondents were deliberately selected with a specific purpose in mind (Punch, 2005). While the study focuses on small firms, the sample was limited to entrepreneurs with over 2 years' of venture establishment experience or those who have already established their products on the market. The reason behind imposing these criteria is to reduce the bias of start-up firms with unproven market penetration and to maintain consistency and homogeneity in our sample.

Table 4 here

Approach. In this study, we organised a series of workshops where we aimed to collect network data by helping respondents visualise their networks. The steps in the workshop were as follows:

In step 1, the respondents were briefed on the study objectives. This was followed with an explanation on the role of networks for entrepreneurship. We started the workshop by asking respondents to fill in a questionnaire investigating types of obstacles and networking approach (see the Appendix). In addition, we asked several questions on founder and firm characteristics.

In step 2, the respondents were asked to generate the names of their network contacts using the egocentric approach or name generator technique (Burt, 1992). This exercise was intended to start the reflective process of looking at networks and contexts. Name generation was not static as respondents could nevertheless add contacts depending on the context. In this step, the information on respondent contacts was collected, including background of contacts, content of conversations, characteristics of their relationship (frequency of interaction, duration of relationship, and respondent's assessment of the closeness of the relationship).

In step 3, to prepare the reflection process and help respondents become familiar with the approach (network visualisation), we asked respondents to draw their current network by referring to the contact names generated in step 2 . The drawing process started by putting contact names (from step 2) on the paper, followed with drawing lines illustrating the relationship including relationship among network contacts. For each relationship, a thick line was used to describe strong ties and a thin line for weak ties. These visual objects help us to measure the level of network density and the strength of ties. In addition, some interviews took place during this activity with the aim of providing a deeper understanding of their networks.

In step 4, the respondents were asked to reflect on their network and networking experience in their entrepreneurial journey. To help the reflection process, respondents were conditioned to think about 
several episodes. We asked respondents to draw their initial network before starting a venture. We also asked them to draw their network when they faced certain difficulties in relation to the context and episodes of their experiences. As a result of this activity, the respondents produced several network maps. For this study, the intention was to measure the change in entrepreneurial networks. Two maps were used as benchmark, the current network map and the initial network map. While the respondents also encouraged to draw their network in certain context during entrepreneurial journey, those maps were used to triangulate the data and confirm the change from the initial to the current network.

As the overall activity was intended to be interactive, rather than simply generating names and drawing a map, the respondents were encouraged to reflect on the nature of their network through discussions and written notes. This process enabled collecting more refined information, such as contacts' backgrounds and the way respondents maintained their relationship with the contacts they identified (frequency of interaction, duration of relationship, and entrepreneurs' assessment of closeness).

In this deductive study, a statistical analysis was performed with the following variables.

\section{Dependent variables}

The dependent variables for this analysis are change in network density and change in network strength. We used the network maps produced in the workshops as the source of data to develop a network matrix consisting of the relationships among respondents' network contacts. In this study, we consider the map representing the initial network (early stage) and the map representing the current network (later stage) to measure network change.

- Network density was measured as the quotient of the total number of ties of network relations $(t)$ and total number of partners ( $n$ ) per spin-off (Borgatti et al, 1998; Jensen and Greve, 2002). A high value indicates a relatively dense network (min: 0 , max: 1 ). To calculate the index, we used the following formula: $2 t /(n(n-1))$. For example, respondent A has five partners, but only two partners are connected to each other. This means that there is one tie present in the network $(t=1)$ and as a result, the network density index is $(2 * 1) /(5 *(5-1))=0.1$.

- The strength of ties was measured as a linear combination of the amount of time, emotional intensity, and frequency of interaction that characterises the tie (Granovetter, 1974). An average three-rank network measurement was used: frequency of face-to-face interactions $(i)$, duration of relationship $(d)$, and entrepreneurs' assessment of closeness of the relationship $(c)$ with partners 
(n) (Burt, 1992). A high value indicates a relatively strong tie (min: 0, max: 1). To calculate the index, we used the following formula. $\left(\frac{\sum_{p=1}^{n} i_{p}+\sum_{p=1}^{n} d_{p}+\sum_{p=1}^{n} c_{p}}{3 n}\right) / 3$

Using these formulas, we calculated the network density and the strength of ties values for the networks developed at the early stage $(x)$ and at the later stage $(y)$. To measure the network change, we calculated the absolute value of the difference between the value from the later stage and the value from the early stage $(|y-x|)$. For instance, the absolute value of the network density change is determined by the network density value at the later stage $(y)$ minus the network density value at the early stage $(x)$

\section{Independent variables}

Networking approach. Following the inductive study, 8 items (see the Appendix) were developed to capture the extent of the networking approach. The interview materials from the second order category were used as a basis for the constructed survey list. All items are five-point scales ranging from 'strongly disagree' to 'strongly agree'. Using factor analysis, we composed a single variable for each category, a networking expansion and a strengthening approach. The study used Cronbach's alpha to test how well a block of indicators measures their corresponding latent construct and DillonGoldstein's rho to assess the unidimensionality of a reflection block. The cross-loadings test (Chin, 1998) was used to examine whether the manifest variables loaded higher on their associated latent variable than any other latent variable. The results are good for both the aforementioned tests. For network expansion, the Cronbach alpha is 0.85 and the Dillon-Goldstein rho is 0.98. For network strengthening, the Cronbach alpha is 0.71 and the Dillon-Goldstein rho is 0.80 . The results are accepted as both values are greater than 0.70 (Fornell and Larcker, 1981).

Obstacles. The obstacles identified in the previous inductive research were classified into two categories, type and source of obstacles. Based on the findings from the inductive study, a list of obstacles was generated (see the Appendix). The respondents were asked to reflect on their experience in developing the business and describe the types of obstacles they encountered. The variables were measured by the number of obstacles.

\section{Control variables}

Several potential control variables were collected in the study. However, a rather low number of sample in the study and the relevancy of those variables in relation to networks reassures us to choose the following variables. 
Number of founders. The number of founders was used as a control variable as firms with more than one founder tend to have a better ability to overcome obstacles and develop networks. A greater number of founders implies more internal resources and hence reducing the need for network change. The variable was measured as number of founders involved in developing the business.

Founders' business experience. Founders with business experience may inherit networks from their previous occupations. Experienced entrepreneurs are more resistant to network changes as their networks have already been built to accommodate their needs during the entrepreneurial process. The variable was measured as the number of years of business experience before starting the current business.

Analysis method. The analysis method used is the partial least squares (PLS) technique of analysing structural equations. PLS was chosen because this study focuses on the prediction of dependent variables (Roldán and Sanchez-Franco, 2012) based on prior models, but introducing new measures and structural paths (Chin, 1998). For this reason, the PLS method seemed the most suitable, particularly as PLS is effective with small samples (Chin and Newsted, 1999), and can address both reflective and formative constructs. According to Cramer (1993), PLS has the ability to produce useful, robust equations even when the number of independent variables or coefficients to be evaluated vastly exceeds the number of experimental observations. Moreover, PLS models are much more stable when the sets of independent variable values are correlated, the most common situation in structure-activity studies such as this.

\section{Results from the second study}

Table 5 shows the number of internal and external obstacles the firms encountered with a relatively high number of internal obstacles. The most common obstacles experienced by the entrepreneurs in the early stage are lack of marketing knowledge and sales skills, followed by lack of managerial and financial skills, and lack of investments. In the later stage, while other obstacles decreased, problems related to marketing and managerial skills increased. Concerning external obstacles, the most common at the early stage relate to knowledge of customer demand and technological change. At the later stage, the obstacles increased and relating largely to market and customer demand as well as technological change.

Table 5 here 
In observing network change, we calculated the value of network change, i.e., network density and network strength, for each entrepreneur and used these for the analysis (Figure 4). Regarding changes in the networks' structural characteristics, the average of network density values show a decline across the two stages. In the early stage, the average of network density value is 0.36 (SD: 0.12) and decreased to only 0.10 (SD:0.09) in the later stage. This finding shows that networks at the beginning were relatively low and the trend decreases even more, meaning that the entrepreneurs had extended their networks even further with some partners unconnected with the previous network. This finding strongly supports Hite's (2005) argument on the emergence of calculative networks where entrepreneurs develop contacts from a different cluster of networks. Moreover, a significant change emerged for the relational characteristics with the average of network strength value of 0.40 (SD: 0.19 ) in the early stage, increasing to 0.55 (SD:0.25) when entering the later stage. This dynamic trend shows that the entrepreneurs started with relatively weak ties but the networks grew stronger as they moved from the early stage to the business growing stage.

Figure 4 here

Table 6 reports the descriptive statistics and correlations among the variables. As the table shows, the control variables are not correlated with any other variables. Worth noting is the negative correlation between the two network changes, indicating that they partially go hand in hand, even if the correlation is not strong. Moreover, the internal obstacles variable is correlated to the network expansion variable, while external obstacles are correlated to the network strengthening variable. As expected, these variables are also correlated to the dependent variables, network density and network strength.

Table 6 here

To test the hypotheses, we used PLS to run the analysis. In the first model, we used the change in network density as a dependent variable to test H1a, while in the second model, the change in network strength was used to test $\mathrm{H} 2 \mathrm{~b}$. To assess the structural (inner) model, this study examined the variance and structural paths. The $R^{2}$ for the latent variables in the model ranges from .30 to .67 (Tables 7 and 8) and is comparable to values typically reported in performance research using PLS (e.g., Fornell and Larcker, 1981). PLS is a nonparametric estimation procedure and does not directly generate an overall goodness of fit index for the structural (inner) model. For this reason, bootstrapping was used (i.e., 
sampling with a replacement method) (Efron, 1979) to extract $t$-values to ascertain the significance of the parameter estimates. Tenenhaus et al. (2005) developed a global effect size measure applicable to PLS path modelling. According to Wetzels et al. (2009), the baseline values for global effect size are defined as small $=.1$; medium $=.25$; and large $=.36$. For the full model, a value of .49 for the network density model and .50 for the network strength model were obtained (Tables 7 and 8), which exceed the base value for large effect sizes of $R 2$, indicating good performance of the structural model.

The first analysis focused on the obstacles and mediating role of networking approaches on influencing the change in network density. As Table 7 shows, the difficulty in acquiring knowledge and skills variable has a positive and significant effect on creating a high-density network $(\beta=.174 ; p$ <.05). In other words, the finding shows that the obstacles encourage entrepreneurs to seek solutions from their high-density network, thus confirming H1a. The difficulty in accessing market and resource obstacles variable has a negative and significant value $(\beta=-.301 ; p<.01)$, confirming H1b. For the networking approach, the analysis found that the network expansion variable is negative and significant $(\beta=-.202 ; p<.05)$. Thus, the result confirms H3a. However, the study cannot confirm H3b as the network strengthening variable is not significant. Concerning the mediation role, the results confirm $\mathrm{H} 4 \mathrm{a}$ where the variable of acquiring knowledge and skills has a significant and positive relationship with network expansion $(\beta=.187 ; p<.05)$, and $\mathrm{H} 4$, where the variable of accessing market and resources has a significant and positive relationship with network strengthening $(\beta=.122$; $p<.10)$.

Table 7 here

In the second analysis, we examined the change in network strength and its relation with the source of obstacles. The internal obstacles variable is negative and significant $(\beta=-.205 ; p<.10)$, indicating the variable is more likely to produce a network with many weak ties. Thus, we confirm $\mathrm{H} 2 \mathrm{a}$. We also found a significant and positive relationship between the external obstacles variable and the network strength variable $(\beta=.134 ; p<.10)$, thus confirming H2b. Moreover, we also found a similar result between the networking approach variable and the change in the strength of ties variable ( $\beta=-.251 ; p<.01$ for network expansion and $\beta=.160 ; p<.10$ for network strengthening). The result confirm both $\mathrm{H} 3 \mathrm{a}$ and $\mathrm{H} 3 \mathrm{~b}$. With regard to the relationship between obstacles and the networking approach, the finding shows that the internal obstacles variable has a significant and positive effect on the network expansion variable $(\beta=.108 ; p<.10)$, while the external obstacles variable has a significant and positive effect on the network strengthening variable $(\beta=.395 ; p<.01)$, thus confirming $\mathrm{H} 4 \mathrm{a}$ and $\mathrm{H} 4 \mathrm{~b}$. 
Table 8 here

The results show that a relationship exists between certain types of obstacles and the networking approach, which suggests that the two competitive networking behaviours are distinct constructs. In this case, the network expansion approach plays a role in mediating internal obstacles, low-density networks with weak ties while the network strengthening approach mediates external obstacles, highdensity networks with strong ties.

\section{Conclusion}

As our review indicates, network researchers typically focus on outcomes, taking available network characteristics as given (Nahapiet and Ghoshal, 1998; Reagans and McEvily, 2003; Semrau and Werner, 2014). Network changes are therefore relatively under-researched (Jack, 2010; Slotte-Kock and Covielo, 2010; Gedajlovic et al., 2013; Porter and Woo, 2015). Although some factors such as similarity, personality, proximity, and organizational structure have been shown to affect network change patterns, more work is needed to understand the antecedents of network changes (Brass et al., 2004). This study therefore advances our understanding of how entrepreneurial networks change and how obstacles and networking approaches may contribute to such change. To achieve our objective, we employed a network visualisation technique to collect entrepreneurial network data in a two-stage study design. The first study sought to identify factors that determine the changes. The second study extended data collection by surveying a larger number of respondents using the obstacles and networking approach constructs developed from the first study to test their impact on network change.

Using an inductive approach, we found that entrepreneurs' networks changed as a response to two factors, the obstacles entrepreneurs face and their approach to managing their networks. Entrepreneurs recognise the need to change the network to accommodate emergent obstacles. Internal obstacles or external obstacles, all led to changes in the entrepreneurs' networks. We found that entrepreneurs adapted and changed their networks to overcome different type of obstacles such as accessing market and resources or acquiring knowledge and skills. In addition, network changes are also influenced by the entrepreneurs' networking approach. On the one hand, entrepreneurs with a network expansion approach are more likely to use every opportunity to create new contacts. On the other hand, entrepreneurs with a network strengthening approach tend to rely on strong, trusting, and close relationships. Looking on the characteristics of network as a result of change, the study found that entrepreneurs often a high-density network with strong ties and a low-density network with weak ties.

Using quantitative survey data, our study confirms that experiencing certain obstacles determines network changes. For entrepreneurs facing internal obstacles and obstacles related to gaining access 
market or resources, the solution to a problem can be facilitated through developing a low-density network with weak ties. Entrepreneurs benefit from a new and innovative approach as a result of connecting to weak ties and a network with structure holes (Granovetter, 1982; Koka et al., 2006). In contrast, to deal with external obstacles and obstacles related to acquiring knowledge and skills, entrepreneurs develop a high-density network with strong ties, as this type of network offers protection and continuous support (Coleman, 1988; Uzzi, Coleman, 1988; Uzzi, 1997). Strong ties are more likely to be useful to entrepreneurs facing threats and uncertainty from external sources (Jack, 2005; Ruef, 2002; Chauvet et al., 2011). Moreover, this study shows that in addition to obstacles, the entrepreneur's networking approach also plays a role in shaping network change (Vissa, 2012). The findings confirm that the network expansion or network strengthening approach significantly influence network changes during the entrepreneurial journey. Entrepreneurs with a network expansion approach are more likely to create a low-density network with weak ties, while entrepreneurs with a network strengthening approach are more like to create a high-density network with strong ties. This study also argues that the entrepreneurs' networking approach is also aligned with the type of obstacles they encounter. Facing obstacles compels entrepreneurs to seek solutions by adapting their networking approach. In this case, internal obstacles or obstacles related to gaining access market or resources induce entrepreneurs to develop a network expansion approach while external obstacles and obstacles related to acquiring knowledge and skills induce entrepreneurs to employ a network-strengthening approach. To summarise, Figure 5 illustrates the results of this study.

Figure 5 here

The findings from this study support the view of network scholars (e.g., Hoang and Antoncic, 2003; Slotte-Kock and Coviello, 2010; Jack, 2010; Sullivan and Ford, 2014) expressing the need to study network changes. In their work, Slotte-Kock and Coviello (2010) identify specific questions (such as what changes, how and why networks change, and what occurs over time) that if addressed would enable a greater understanding of network changes and development. Our study is the first to our knowledge that studies types of obstacles and networking approaches as determinants of network changes, and hypothesises that both factors have an impact on network changes. The contribution of our research lies in illustrating how entrepreneurs change their network as a way of overcoming obstacles, but also that change is constrained by the entrepreneurs' networking approach. The findings of this study help us move towards a general network change phenomenon. 
Secondly, we examined how entrepreneurs develop their networks using a less traditional approach. The interactive workshop and the network mapping approach successfully generated sufficient depth of data to explore network changes in response to entrepreneurial requirements. The nature of our findings and the conclusions we have arrived at lead us to deem that elements of these could reflect the situations of others immersed in similar contexts within the UK and further afield, but realise that this can only be confirmed through further work and testing our results. An important implication for practitioners, such as incubator managers, is that organizational support enables entrepreneurs to develop their networks. Our findings suggest that the obstacles entrepreneurs face may induce them to seek solutions leading to a network change. Facilitating reaching and engaging with new contacts is particularly important for entrepreneurs with limited skills, but confident in networking.

Despite the above contributions, our study has some limitations. First, there is always a potential memory problem in revealing networks, especially in the early stage. Although we put a great deal of effort into reducing the problem by giving considerable space for reflection and posing a series of questions, there is a possibility that respondents omitted details in developing their networks. Second, we have not accounted for the fact that the entrepreneurs may have learned during the entrepreneurial process. If the entrepreneurial process is considered a learning process, they may have adapted their approach to respond to their needs. Third, while this research examines two key factors that determine changes in the entrepreneurial network, future research could consider other factors, such as the availability of network partners and their characteristics. There is also a need to validate our findings in other contexts. The respondents of our study were located in the Northwest region of the United Kingdom and were involved in a university-SME engagement activity. We are aware that one of the criticisms that purposeful sampling faces is that it can cause distortion through insufficient breadth (Patton, 1990). However, for this particular study, we felt it appropriate as the situations of respondents meant they were open, familiar with our approach, and willing to participate in research activity. An avenue of interest for future studies is how networking practices develop during the entrepreneurial journey.

\section{References}

Adler, P. and S. W. Kwon, 2002, "Social capital: Prospects for a new concept". Academy of Management Review, 27(1): 17-40.

Ahuja, G., 2000, "Collaboration networks, structural holes, and innovation: A longitudinal study". Administrative Science Quarterly, 45(3): 425-455.

Aldrich, H.E. and P. R. Reese, 1993, "Does networking pay off? A panel study of entrepreneurs in the research triangle”. In Churchill et al. (Eds.) Frontiers of Entrepreneurship Research: 325-399, Babson College: Babson, MA. 
Anderson, A. R. and S. K. Jack, 2002, "The articulation of social capital in entrepreneurial networks: a glue or a lubricant?" Entrepreneurship and Regional Development, 14(3): 193-210.

Baum, J. A., T. Calabrese and B. S. Silverman, 2000, "Don't go it alone: Alliance network composition and startups' performance in Canadian biotechnology". Strategic management journal, 267-294.

Beckman, C. M., P. R. Haunschild and D. J. Phillips, 2004, "Friends or strangers? Firm-specific uncertainty, market uncertainty, and network partner selection”. Organization science, 15(3): 259-275.

Birley, S., 1985, "The role of network in the entrepreneurial process". Journal of Business Venturing, 1(1): 107-117.

Borgatti, S. P., C. Jones and M. G. Everett, 1998, "Network measures of social capital". Connection, 21(2): 27-36.

Brass, D. J., J. Galaskiewicz, H. R. Greve and W. Tsai, 2004, Taking stock of networks and organizations: A multilevel perspective. Academy of Management Journal, 47: 795-817.

Brown, B. and J. E. Butler, 1995, "Competitors as allies: a study of entrepreneurial networks in the US wine industry". Journal of Small Business Management, 33: 57-57.

Burt, R., 1992, Structural holes. Cambridge: Harvard University Press.

Burt, R., 2000, "The network structure of social capital". In B.M. Staw and R. I. Sutton (Eds.) Research in organizational behaviour: 22: 345-423. Greenwich, CT: JAI Press.

Burt, R., 2004, "Structural holes and good ideas", American Journal of Sociology, 110(2): 349-399.

Cattani, G. and S. Ferriani, 2008, "A core/periphery perspective on individual creative performance: Social Networks and Cinematic Achievements in the Hollywood film Industry". Organization Science, 19: 824-844.

Chauvet, V., B. Chollet, G. Soda and I. Hualt, 2011, "The contribution of network research to managerial culture and practice", European Management Journal, 29(5): 321-334.

Chin, W. W., 1998, “The partial least squares approach to structural equation modelling”. Modern Methods for Business Research, 295(2): 295-336.

Chin, W. W. and P. R. Newsted, 1999, "Structural equation modeling analysis with small samples using partial least squares”. Statistical Strategies for Small Sample Research, 1(1): 307-341.

Coleman, J. S., 1988, "Social capital in the creation of human capital". American Journal of Sociology, 94: 95-120.

Cramer, R. D., 1993, "Partial least squares (PLS): its strengths and limitations". Perspectives in Drug Discovery and Design, 1(2): 269-278.

Davidsson, P. and B. Honig, 2003, "The role of social and human capital among nascent entrepreneurs". Journal of Business Venturing, 18(3): 301-331. 
Dyer, J. H., H. B. Gregersen and C. Christensen, 2008, "Entrepreneur behaviors, opportunity recognition, and the origins of innovative ventures". Strategic Entrepreneurship Journal, 2(4): 317-338

Efron, B., 1979, "Computers and the theory of statistics: thinking the unthinkable". SIAM Review, 21(4): 460-480.

Elfring, T. and W. Hulsink, 2007, "Networking by Entrepreneurs: Patterns of Tie-Formation in Emerging Organizations”. Organization Studies, 28(12): 1849-1872.

Fontana, A. and J. Frey, 1994, "The art of science". The Handbook of Qualitative Research, 361-376.

Fornell, C. and D. F. Larcker, 1981, "Structural equation models with unobservable variables and measurement error: Algebra and statistics". Journal of Marketing Research, 382-388.

Galaskiewicz, J. and D. Shatin, 1981, "Leadership and networking among neighborhood human service organizations". Administrative Science Quarterly, 434-448.

Gedajlovic, E., B. Honig, C. B. Moore, G. T. Payne and M. Wright, 2013, "Social capital and entrepreneurship: A schema and research agenda". Entrepreneurship Theory and Practice, 37(3): 455-478.

Glaser, B. and A. Strauss, 1967, The discovery of grounded theory. Weidenfield \& Nicolson, London, $1-19$.

Granovetter, M., 1974, “The strength of weak ties", American Journal of Sociology, 78(6): 13601380.

Granovetter, M., 1982, "The strength of weak ties: A network theory revisited", in P.V. Marsden and Nan Lin (Eds.). Social structure and network analysis. Beverly Hills: Sage.

Gummesson, E., 2000, Qualitative methods in management research. Sage.

Gulati, R., 1995, "Social structure and alliance formation patterns: A longitudinal analysis”. Administrative Science Quarterly, 619-652.

Hallen, B. L., 2008, "The causes and consequences of the initial network positions of new organizations: From whom do entrepreneurs receive investments?" Administrative Science Quarterly, 53(4): 685-718.

Hite, J., 2005, "Evolutionary processes and paths of relationally embedded network ties in emerging entrepreneurial firms", Entrepreneurship Theory and Practice, January: 113-144.

Hite, J. M. and W. S. Hesterly, 2001, "The evolution of firm networks: From emergence to early growth of the firm". Strategic Management Journal, 22(3): 275-286.

Hoang, H. and B. Antoncic, 2003, "Network-based research in entrepreneurship: A critical review", Journal of Business Venturing, 18(2): 165-187.

Inkpen, A. C. and E. W. Tsang, 2005. "Social capital, networks, and knowledge transfer". Academy of management review, 30(1): 146-165.

Jack, S. L., 2005, "The Role, Use and Activation of Strong and Weak Network Ties: A Qualitative Analysis". Journal of Management Studies, 42(6): 1233-1259. 
Jack, S. L., 2010, "Approaches to studying networks: Implications and outcomes". Journal of Business Venturing, 25(1): 120-137

Jarillo, J. C., 1988, “On strategic networks”. Strategic Management Journal, 9(1): 31-41.

Jensen, J. I. and A. Greve, 2002, "Does the Degree of Redundancy in Social Networks Influence the Success of Business Start-ups?" International Journal of Entrepreneurial Behavior and Research, 8: 254-267.

Johannisson, B., 1986, "Network strategies: management technology for entrepreneurship and change". International Small Business Journal, 5(1): 19-30.

Koka, B. R., R. Madhavan and J. E. Prescott, 2006, "The evolution of interfirm networks: Environmental effects on patterns of network change". Academy of Management Review, 31(3), 721-737.

Larson, A. and J. Starr, 1993, "A network model of organization formation”. Entrepreneurship Theory and Practice, Winter: 5-15.

Locke, K., 2001, Grounded theory in management research. Sage.

McEvily, B. and A. Zaheer, 1999, "Bridging ties: A source of firm heterogeneity in competitive capabilities". Strategic Management Journal, 1133-1156.

Miles, M. B. and A. M. Huberman, 1994, Qualitative data analysis: A sourcebook. Beverly Hills: Sage Publications.

Mintzberg, H., 1997, “Crafting strategy”. Harvard Business Review, July-August: 66-75.

Nahapiet, J. and S. Ghoshal, 1998, "Social capital, intellectual capital, and the organizational advantage". Academy of Management Review, 23(2): 242-266.

Obstfeld, D., 2005, "Social Networks, the Tertius Iungens Orientation, and Involvement in Innovation". Administrative Science Quarterly, 50: 100-130

O'Donnell, A., 2014, “The contribution of networking to small firm marketing”. Journal of Small Business Management, 52(1): 164-187.

O'Donnell, A., A. Gilmore, D. Cummins and D. Carson, 2001, "The network construct in entrepreneurship research: a review and critique”. Management Decision, 39(9): 749-760.

Perry-Smith, J. E. and P. V. Mannucci, 2017, "From creativity to innovation: The social network drivers of the four phases of the idea journey". Academy of Management Review, 42(1): 53-79.

Patton, M. Q, 1990, Qualitative evaluation and research methods. Newbury Park, CA: SAGE.

Piaget, J., 1971. "The theory of stages in cognitive development”. In D. R. Green, M. P. Ford, \& G. B. Flamer (Eds.), Measurement and Piaget. New York: McGraw-Hill.

Podolny, J. M., 1994, "Market uncertainty and the social character of economic exchange". Administrative Science Quarterly, 458-483.

Podolny, J. M. and J. N. Baron, 1997, "Resources and relationships: Social networks and mobility in the workplace". American Sociological Review, 673-693. 
Porter, C. M. and S. E. Woo, 2015, "Untangling the networking phenomenon: A dynamic psychological perspective on how and why people network". Journal of Management, 41(5): $1477-1500$.

Punch, K.F., 2005. Introduction to social science research: quantitative and qualitative approach, Sage publication, London.

Reagans, R. and B. McEvily, 2003, "Network structure and knowledge transfer: The effects of cohesion and range". Administrative science quarterly, 48(2): 240-267.

Roldán, J. L. and M. J. Sánchez-Franco, 2012, "Variance-based structural equation modeling: guidelines for using partial least squares". Research methodologies, innovations and philosophies in software systems engineering and information systems, 193.

Ruef, M., 2002, "Strong ties, weak ties and islands: structural and cultural predictors of organizational innovation". Industrial and Corporate Change, 11(3): 427-449.

Sapienza, H. J., 1992, “When do venture capitalists add value?” Journal of Business Venturing, 7(1): 9-27.

Schutjens, V. and E. Stam, 2003, "The evolution and nature of young firm networks: A longitudinal perspective". Small Business Economics, 21(2): 115-134.

Semrau, T. and A. Werner, 2014, "How Exactly Do Network Relationships Pay Off? The Effects of Network Size and Relationship Quality on Access to Start- Up Resources”. Entrepreneurship Theory and Practice, 38(3): 501-525.

Shea, C. T. and G. M. Fitzsimons, 2016, "Personal goal pursuit as an antecedent to social network structure”. Organizational Behavior and Human Decision Processes, 137: 45-57.

Shipilov, A., G. Labianca, V. Kalnysh and Y. Kalnysh, 2007, "Career-related network building behaviors, range social capital and career outcomes". Best Papers Proceedings, 67th Annual Conference of the Academy of Management, Philadelphia, PA.

Silverman, D., 2006, Interpreting qualitative data: Methods for analyzing talk, text and interaction. Sage.

Simsek, Z., M. H. Lubatkin and S. W. Floyd, 2003, "Inter-firm networks and entrepreneurial behavior: A structural embeddedness perspective”. Journal of Management, 29(3): 427-442.

Sjöstrand, S. E., 1992, "On the rationale behind "irrational" institutions". Journal of Economic Issues, 26(4): 1007-1040.

Slotte- Kock, S. and N. Coviello, 2010, "Entrepreneurship research on network processes: a review and ways forward". Entrepreneurship Theory and Practice, 34(1): 31-57

Sorenson, O. and T. E. Stuart, 2001, "Syndication Networks and the Spatial Distribution of Venture Capital Investments”. American Journal of Sociology, 106 (6): 1546-1588.

Street, C. T. and A. F. Cameron, 2007, "External relationships and the small business: A review of small business alliance and network research". Journal of Small Business Management, 45(2), 239-266. 
Sullivan, D. M., \& Ford, C. M. (2014). How entrepreneurs use networks to address changing resource requirements during early venture development. Entrepreneurship Theory and Practice, 38(3), $551-574$.

Tenenhaus, M., E. V. Vinzi, Y. M. Chatelin and C. Lauro, 2005, "PLS path modelling". Computational Statistics \& Data Analysis, 48(1): 159-205.

Uzzi, B., 1997. "Social structure and competition in interfirm network: the paradox of embeddedness". Administrative Science Quarterly, 42(1): 35-67.

Uzzi, B. and Gillespie, J.J., 2002, "Knowledge spillover in corporate financing networks: Embeddedness and the fir's debt performance". Strategic Management Journal, 23: 595-618.

Van de Ven, A. H., 1986, "Central problems in the management of innovation". Management Science, 32(5): 590-607.

Venkataraman, S. and A. H. Van de Ven, 1998, "Hostile environmental jolts, transaction set, and new business". Journal of Business Venturing, 13(3): 231-255.

Vissa, B., 2011, "A matching theory of entrepreneurs' tie formation intentions and initiation of economic exchange". Academy of Management Journal, 54(1): 137-158.

Vissa, B., 2012, “Agency in action: Entrepreneurs' networking style and initiation of economic exchange". Organization Science, 23(2):492-510.

Wetzels, M., G. Odekerken-Schröder and C. Van Oppen, 2009, "Using PLS path modeling for assessing hierarchical construct models: Guidelines and empirical illustration”. MIS Quarterly, 177-195.

Yin, R. K., 2002, Applications of Case Study Research Second Edition (Applied Social Research Methods Series Volume 34).

Zaheer, A. and G. G. Bell, 2005, "Benefiting from network position: firm capabilities, structural holes, and performance". Strategic Management Journal, 26(9): 809-825.

\section{Appendix}

\section{List of questions on internal and external obstacles}

Please tick if you have experienced the following obstacles:

The

The growth stage

establishment

stage

Lack of marketing knowledge and sales skills

Lack of access to research and development facilities

Lack of technological capability

Lack of managerial and financial skills 
Lack of investments

Lack of knowledge about customer demand including

market

Dealing with technological change

Dealing with market demand

Dealing with competition and industrial structure

Dealing with regulations, standardisation, and bureaucracy

Other (please explain)

\section{List of questions on the networking approach}

Below are a number of statements regarding your networking approach, please rate to what extent the following statements represents your approach in developing your network.

(1) strongly disagree (2) disagree (3) neither agree nor disagree (4) agree (5) strongly agree

- In developing my network, I often use social media (e.g., LinkedIn, Facebook, Twitter, etc.) or make a direct phone call

- When I attend networking events (e.g., events organised by associations, exhibitions, etc.), I easily build connections with people that I did not know before

- I am actively involved in social activities (e.g., social club, social organisation, etc.) to meet new contacts.

- When I build a relationship, my consideration is to find out if s/he has resources/expertise that I need

- I find it difficult to discuss my business with my contacts without building a long and stable relationship.

- I prefer to seek support from family, friends, and long-term colleagues/friends

- I socialise with my contacts and build friendships outside the business

- When developing a relationship, I always consider the long-term mutual benefits. 